\title{
Pencegahan Stunting Pada Anak Di Desa Tamangapa Kec. Ma'rang Kab. Pangkep
}

${ }^{1}$ Ayu Puspitasari, ${ }^{2}$ Wudi Darul Putra, ${ }^{3}$ Haeril Amir

123 Universitas Muslim Indonesia

Korespondensi: ayupuspitasari@umi.ac.id

\begin{abstract}
This community service is carried out as a form of the Tri Dharma of Higher Education, community service by raising the theme of counseling on stunting prevention in children is not without reason but because most people do not understand correctly about stunting, and assume that stunting or stunted as the term commonly used in society is a factor. descendants. This community service activity is carried out to increase knowledge and understanding as well as community participation in stunting prevention and early detection programs in toddlers which are expected to directly motivate the community to participate in paying attention to the growth and development of their children so that their growth and development can be optimal. The method of implementing community service with direct counseling techniques to the community. The results of the service, in general, the counseling participants said that their knowledge of stunting increased and was even better committed to assisting children's growth and development.
\end{abstract}

\begin{abstract}
ABSTRAK
Pengabdian masyarakat ini dilaksanakan sebagai wujud Tri Dharma Perguruan Tinggi, pengabdian masyarakat dengan mengangkat tema penyuluhan pencegahan stunting pada anak bukanlah tanpa alasan tetapi melihat sebagian besar masyarakat belum paham dengan benar mengenai stunting, dan beranggapan bahwa stunting atau kerdil sebutan yang biasa digunakan di masyarakat adalah faktor keturunan. Kegiatan pengabdian pada masyarakat ini dilakukan untuk meningkatkan pengetahuan dan pemahaman serta peran serta masyarakat dalam program pencegahan dan deteksi dini stunting pada balita yang diharapkan secara langsung dapat memotivasi masyarakat untuk ikut serta memperhatikan pertumbuhan dan perkembangan pada anaknya sehingga pertumbuhan dan perkembangannya dapat optimal. Metode pelaksanaan pengabdian dengan Teknik penyuluhan langsung kepada masyarakat. Hasil pengabdian, secara umum peserta penyuluhan mengatakan pengetahuan mereka terhadap stunting meningkat dan berkomitmen lebih baik lagi dalam mendampingi tumbuh kembang anak.
\end{abstract}

Kata Kunci : Stunting, Penyuluhan, Pengabdian Masyarakat

\section{PENDAHULUAN}

Hasil Riset Kesehatan Dasar Tahun 2013, prevalensi stunting di Indonesia mencapai 37,2 \%. Berdasarkan Pemantauan Gizi Tahun 2016, mencapai 27,5\% sedangkan WHO memberikan batasan untuk stunting adalah $<20 \%$. Hal ini menunujukkan bahwa pertumbuhan yang tidak maksimal dialami oleh sekitar 8,9 juta anak di Indonesia atau 1 dari 3 anak mengalami stunting. Selain itu lebih dari 1/3 anak berusia dibawah 5 tahun di Indonesia tinggai badannya di bawah rata-rata. ${ }^{1}$

Desa Tamangapa Kabupaten Pangkep merupakah salah satu Desa di Kecamatan Parangloe dengan jumlah penduduk sebanyak 3100 jiwa. Tingginya angka kejadian stunting menjadi perhatian pemerintah. Beberapa penyebab stunting itu sendiri adalah kurangnya asupan yang diserap oleh tubuh mulai dari masih didalam kandungan sampai dengan setelah lahir, kurangnya akses ke pelayanan kesehatan, kurangnya akses air bersih dan sanitasi. Oleh karena itu perlu dilakukan upaya pencegahan stunting dengan perbaikan pola makan, pola asuh dan sanitasi. ${ }^{2}$

Besarnya kerugian yang ditanggung akibat stunting lantaran naiknya pengeluaran pemerintah terutama jaminan kesehatan nasional yang berhubungan dengan penyakit tidak menular seperti jantung, stroke, diabetes atapun gagal ginjal. Ketika dewasa, anak yang menderita stunting mudah mengalami

This is an open-access article under the CC BY 4.0 International License

(C) Idea Pengabdian Masyarakat (2021)

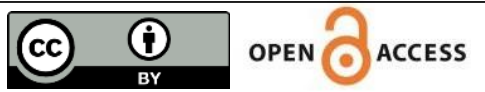


kegemukan sehingga rentan terhadap serangan penyakit tidak menular seperti jantung, stroke ataupun diabetes.

Menurut data statistik, desa Tamangapa termasuk salah satu desa miskin yang ada di Kec.Ma'rang. Secara garis administratif desa ini berada di kawasan pesisir, karena salah satu dusunya berbatasan langsung dengan Kec. Liukang Tupabbiring Utara. ${ }^{3}$

Mata pencaharian dari warga desa ini adalah Nelayan, Petani Rumput Laut, Petani Tambak, Petani Sawah, buruh tani, pekebun Jeruk dan pedagang. Luas lahan pertanian dan pertambakan kurang lebih $300 \mathrm{Ha}$ namun disektor pertambakan saat ini mengalami masa suram sehingga para petambak banting setir ke kegiatan lain seperti bertani rumput laut, tukang ojek, tukang batu, dll.

Pendidikan kesehatan merupakan suatu metode mendorong dan meningkatkan pengetahuan Masyarakat sehingga menurut Notoatmojo pendidikan kesehatan melalui penyuluhan dapat mempertahankan derajat kesehatan disamping itu dapat juga mencegah datangnya penyakit. ${ }^{4}$

\section{Metode Pelaksanaan}

Penyuluhan kesehatan ini kami bagi dalam beberapa metode pelaksanaan yakni sosialisasi, penyuluhan dan penyebaran Leaflet edukasi pencegahan stunting.

Tahap 1 Sosialisasi

Sosialisasi dilakukan 3 hari sebelum kegiatan dilakukan yakni selasa 25 Mei 2021. sosialisasi dilakuakan bersama dengan kader Pemerintah Desa Lonjoboko dan Masyarakat Desa Lonjoboko.

Tahap II Penyuluhan Kesehatan

Tahap Penyuluhan dilakukan langsung pada tanggal 30 Mei 2021 dan dilakukan berdasarkan standar Kemenkes RI yakni sebagai Berikut:

1. Memenuhi kebutuhan gizi sejak hamil. Tindakan yang relatif ampuh dilakukan untuk mencegah stunting pada anak adalah selalu memenuhi gizi sejak masa kehamilan

2. Beri ASI Eksklusif sampai bayi berusia 6 bulan. Veronika Scherbaum, ahli nutrisi dari Universitas Hohenheim, Jerman, menyatakan ASI ternyata berpotensi mengurangi peluang stunting pada anak berkat kandungan gizi mikro dan makro.

3. Dampingi ASI Eksklusif dengan MPASI sehat. Ketika bayi menginjak usia 6 bulan ke atas, maka ibu sudah bisa memberikan makanan pendamping atau MPASI. Dalam hal ini pastikan makananmakanan yang dipilih bisa memenuhi gizi mikro dan makro yang sebelumnya selalu berasal dari ASI untuk mencegah stunting.

4. Terus memantau tumbuh kembang anak. Orang tua perlu terus memantau tumbuh kembang anak mereka, terutama dari tinggi dan berat badan anak. Bawa si Kecil secara berkala ke Posyandu maupun klinik khusus anak. Dengan begitu, akan lebih mudah bagi ibu untuk mengetahui gejala awal gangguan dan penanganannya.

5. Selalu jaga kebersihan lingkungan. Seperti yang diketahui, anak-anak sangat rentan akan serangan penyakit, terutama kalau lingkungan sekitar mereka kotor. Faktor ini pula yang secara tak langsung meningkatkan peluang stunting.

Tahap III Pembagian Leaflet dan Poster

Pembagian Leaflet dan poster dilakukan pada hari yang sama, kbertujuan agar masyarakat melihat langsung melalui media yang dibagikan mengenai pencegahan stunting pada anak, leaflet dibagikan dengan bahasa sederhana disertai gambar yang menarik agar masayarakat tidak kesulitan saat membaca dan memahami.

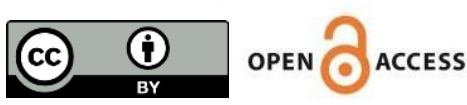




\section{HASIL DAN PEMBAHASAN}

Penyuluhan Kesehatan

Kegiatan ini bertujuan memberikan pengetahun serta edukasi kepada Masyarakat tentang perlunya pencegahan stunting pada anak, pada saat akhir kegiatan Tim melakukan evaluasi dan respon masyarakat sangat Positif mengenai komitmen mereka dalam melaksanakan pencegahan stunting dilingkungan rumah tangga.

\section{Pembagian Leaflet}

Pembagian leaflet bertujuan agar masyarakat memahami melalui media gambar tentang pentingnya pencegahan stunting pada anak, salah satu penyebab masyarakat kurang memiliki pengetahuan mengenai stunting karena sulitnya akses informasi yang didapatkan dak kurangnya edukasi secara berkesinambungan dari pihak-pihak terkait.

Tabel 1

\begin{tabular}{c|l|c}
\hline No. & \multicolumn{1}{|c|}{ Nama Kegiatan } & \multicolumn{1}{c}{ Ket. } \\
\hline 1 & $\begin{array}{l}\text { Penyuluhan } \\
\text { pencegahan stunting } \\
\text { pada anak }\end{array}$ & Terlaksana \\
\hline 2 & $\begin{array}{l}\text { Kewenangan Desa dan } \\
\text { Impilkasinya }\end{array}$ & Terlaksana \\
\hline
\end{tabular}
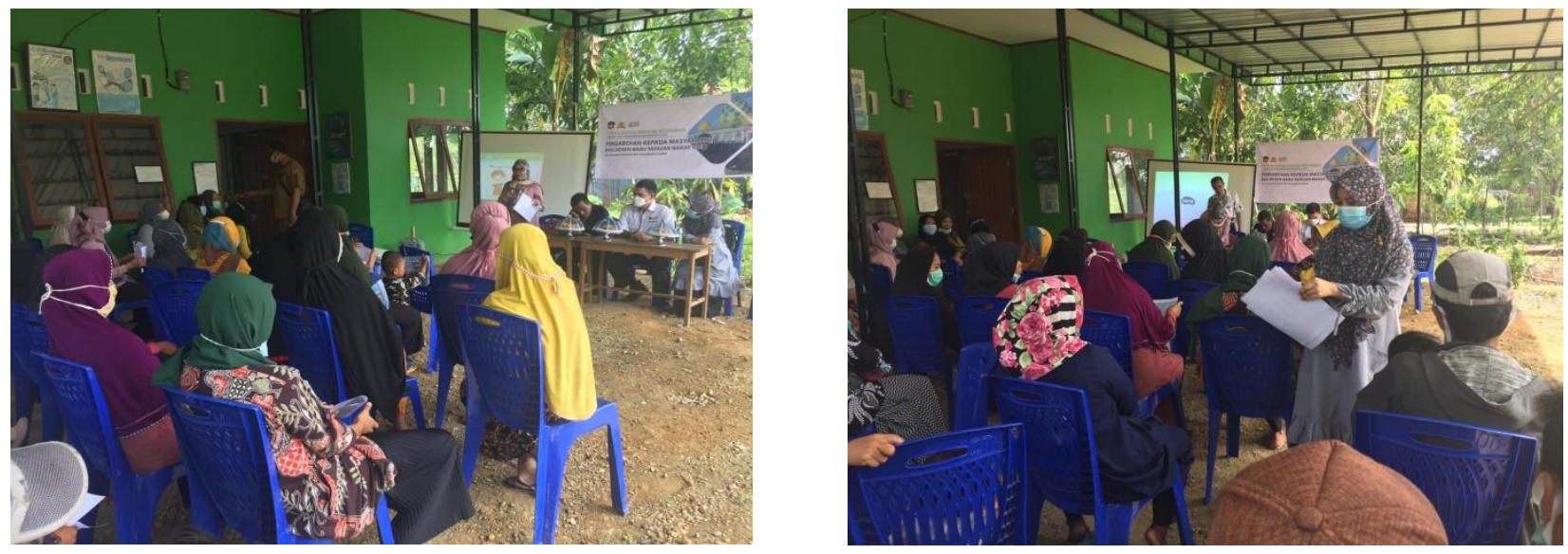

Gambar 1 dan 2 : Penyuluhan di Balai Desa Tamangapa Kec. Ma'rang

\section{KESIMPULAN}

Kegiatan penyuluhan kesehatan kepada masyarakat mengenai pencegahan stunting pada anak sangat penting dilakukan, mengingat aset penting bangsa adalah sumber daya manusia yang harus diperhatikan tumbuh kembangnya sehingga menghasilkan generasi gemilang dimasa akan datang. Pengabdian masyarakat yang dilakukan oleh Dosen adalah upaya membantu pemerintah dalam mensukseskan kebijakan serta bentuk pengimplementasian perguruan tinggi dalam melakasanakan Tri Dharma Perguruan Tinggi. 


\section{UCAPAN TERIMAKASIH}

Terimakasih Kepada Pemerintah Kabupaten Pangkep, Pemerintah Desa Tamangapa dan TIM Dosen serta LPkM Universitas Muslim Indonesia.

\section{DAFTAR PUSTAKA}

1. Kementrian Desa, Pembangunan Daerah Tertinggal dan Transmigrasi. 2017. Buku Saku Desa Dalam Penanganan Stunting. Jakarta : Kementrian Desa, Pembangunan Daerah Tertinggal dan Transmigrasi.

2. KEMENKES RI. (2018). ini penyebab Stunting pada anak. Retrieved from http://www.depkes.go.id/article/view/18052800006/ini-penyebabstunting -pada-anak.htm

3. BPS. Kecamatan Ma'rang Dalam Angka 2020. Badan Pusat Statistik Pangakejene Dan Kepulauan. 2020.

4. Notoatmojo. Pendidikan dan Perilaku Kesehatan. Jakarta: Rineka Cipta; 2010.

This is an open-access article under the CC BY 4.0 International License

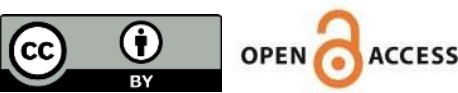

(C) Idea Pengabdian Masyarakat (2021) 